\title{
Processing of Retinal and Extraretinal Signals for Memory-Guided Saccades During Smooth Pursuit
}

\author{
Gunnar Blohm, ${ }^{1,2}$ Marcus Missal, ${ }^{2}$ and Philippe Lefèvre ${ }^{1,2,3}$ \\ ${ }^{1}$ Centre for Systems Engineering and Applied Mechanics, Université Catholique de Louvain, Louvain-la-Neuve, Belgium; ${ }^{2}$ Laboratory of \\ Neurophysiology, Université Catholique de Louvain, Brussels, Belgium; and ${ }^{3}$ National Eye Institute, National Institutes of Health, \\ Bethesda, Maryland
}

Submitted 25 May 2004; accepted in final form 10 October 2004

\begin{abstract}
Blohm, Gunnar, Marcus Missal, and Philippe Lefèvre. Processing of retinal and extraretinal signals for memory-guided saccades during smooth pursuit. J Neurophysiol 93: 1510-1522, 2005. First published October 13, 2004; doi:10.1152/jn.00543.2004. It is an essential feature for the visual system to keep track of self-motion to maintain space constancy. Therefore the saccadic system uses extraretinal information about previous saccades to update the internal representation of memorized targets, an ability that has been identified in behavioral and electrophysiological studies. However, a smooth eye movement induced in the latency period of a memory-guided saccade yielded contradictory results. Indeed some studies described spatially accurate saccades, whereas others reported retinal coding of saccades. Today, it is still unclear how the saccadic system keeps track of smooth eye movements in the absence of vision. Here, we developed an original two-dimensional behavioral paradigm to further investigate how smooth eye displacements could be compensated to ensure space constancy. Human subjects were required to pursue a moving target and to orient their eyes toward the memorized position of a briefly presented second target (flash) once it appeared. The analysis of the first orientation saccade revealed a bimodal latency distribution related to two different saccade programming strategies. Short-latency $(<175 \mathrm{~ms})$ saccades were coded using the only available retinal information, i.e., position error. In addition to position error, longerlatency $(>175 \mathrm{~ms}$ ) saccades used extraretinal information about the smooth eye displacement during the latency period to program spatially more accurate saccades. Sensory parameters at the moment of the flash (retinal position error and eye velocity) influenced the choice between both strategies. We hypothesize that this tradeoff between speed and accuracy of the saccadic response reveals the presence of two coupled neural pathways for saccadic programming. A fast striatal-collicular pathway might only use retinal information about the flash location to program the first saccade. The slower pathway could involve the posterior parietal cortex to update the internal representation of the flash once extraretinal smooth eye displacement information becomes available to the system.
\end{abstract}

\section{IN T R O D U C T I O N}

Space constancy is an essential feature of the visual system that allows us to perceive a stationary object as immobile during self-movement even though its image shifts across the retina (Bridgeman 1995; Deubel et al. 1998; Niemann and Hoffmann 1997; Stark and Bridgeman 1983). In the case where visual information is absent, the question arises whether space constancy of memorized targets still holds during eye movements. This issue has been extensively studied for the saccadic system using the so-called double-step and colliding saccade

Address for reprint requests and other correspondence: P. Lefèvre, CESAME, Université Catholique de Louvain, 4, Avenue G. Lemaître, 1348 Louvain-la-Neuve, Belgium (E-mail: lefevre@csam.ucl.ac.be). paradigms (Aslin and Shea 1987; Becker and Jürgens 1979; Dassonville et al. 1992; Dominey et al. 1997; Goossens and Van Opstal 1997; Hallett and Lightstone 1976a,b; Mays and Sparks 1980; Mushiake et al. 1999; Schlag and Schlag-Rey 1990; Schlag et al. 1989; Tian et al. 2000). In both experimental conditions, a saccadic eye movement is evoked either visually or by microstimulation before primates have to direct their line of sight to a previously memorized spatial location. In this situation, the retinal error of the memorized target does not correspond anymore to the required eye movement. Nevertheless, saccades are spatially accurate. The authors conclude that extra-retinal information about the first eye movement is available to the saccadic system to adapt the second saccade amplitude. The saccadic system is thus able to keep track of its own movements.

During smooth-pursuit movements, the question of space constancy becomes more complicated. In this case, a smooth eye movement is induced before the occurrence of the saccade directed toward the memorized target. Again, to align gaze with the correct spatial location of the memorized target, the retinal input has to be updated by extraretinal signals about the smooth eye displacement. Thus the saccadic system needs additional information from another motor system-the smooth-pursuit system-to compensate for smooth eye displacements. Today, it is still not clear how such memoryguided saccades are programmed during smooth eye movements. Recent studies indicate that gaze shifts to targets memorized before visually guided smooth pursuit and executed after the end of pursuit are spatially accurate (Baker et al. 2003; Herter and Guitton 1998). Also, when targets were briefly flashed during smooth pursuit but the localization was performed only after the smooth-pursuit target disappeared, memory-guided saccades seemed to be better predicted by the spatial error hypothesis (i.e., saccades directed to the actual target position in space, accounting for the retinal error and intervening movements during the latency period) than by the retinal error hypothesis (i.e., saccade directed to the retinal position of the target irrespective of intervening eye movements) (Ohtsuka 1994; Schlag et al. 1990; Zivotofsky et al. 1996). Taken together, these results suggest that the saccadic system has indeed access to information about smooth eye displacement during the memory period. However, when a target is briefly flashed at the moment of the smooth-pursuit target extinction and a targeting saccade is immediately trig-

The costs of publication of this article were defrayed in part by the payment of page charges. The article must therefore be hereby marked "advertisement" in accordance with 18 U.S.C. Section 1734 solely to indicate this fact. 
gered, its amplitude is better predicted by the retinal error than by the spatial error (Gellman and Fletcher 1992; McKenzie and Lisberger 1986). These results are clearly contradictory with the above-mentioned hypothesis of space constancy during smooth eye movements and the question arises what can explain this apparent contradiction.

To answer this question, we propose to investigate how memory-guided saccades are programmed during smooth pursuit. In particular, because long memory periods seemed to allow space constancy during self-generated movement (Baker et al. 2003; Herter and Guitton 1998; Ohtsuka 1994; Schlag et al. 1990; Zivotofsky et al. 1996), whereas this was not the case for short memory periods (Gellman and Fletcher 1992; McKenzie and Lisberger 1986), we will investigate the role of response latency in the saccade programming process. By doing this, we will be able to make the link between the above-mentioned results of short-latency retinal and longlatency spatial saccade programming. Therefore we developed a two-dimensional (2-D) experimental paradigm in which we presented a briefly flashed target during smooth-pursuit eye movements. This 2-D arrangement of the paradigm allowed us to separate retinal and extraretinal signals and to obtain saccade programming parameters for horizontal and vertical eye-movement components separately. Furthermore, a detailed analysis of saccade latencies made it possible for the first time to link the saccadic execution time to the programming of the memory-guided eye movement. As a result, we will show that there is a transition between retinally coded short-latency saccades and spatially coded longer-latency eye saccades and that this transition is reflected in a bimodal saccadic latency distribution. We will also analyze which sensory parameters influence the system's decision to trigger short- or longer-latency saccades. These results shed light on the use of extra-retinal signals when tracking smooth eye movements in the absence of visual input and reconcile previous contradictory results concerning the programming of memory-guided saccades during smooth self-motion. Our paradigm thus allowed us to identify two coupled processes for saccade execution.

\section{METHODS}

Eight healthy human subjects aged between 23 and 38 yr and without any known oculomotor anomalies were recruited after informed consent. Three of them were completely naïve of oculomotor experiments. All procedures were conducted with approval of the Université Catholique de Louvain Ethics Committee, in compliance with the Helsinki Declaration (1996).

\section{Experimental setup}

Subjects faced a $1-\mathrm{m}$ distant, tangent translucent screen that covered about $\pm 45^{\circ}$ horizontally and $\pm 40^{\circ}$ vertically of their visual field. They sat in complete darkness and their head was restrained using a chin rest. Two different targets - a green and a red spot- were back-projected onto the screen. The green spot was projected by a Tektronix (Beaverton, OR) 606A oscilloscope using custom optics and measured $\sim 1.5^{\circ}$. This green spot was the smooth-pursuit target. A second target was a red laser spot that measured $0.2^{\circ}$ and was projected onto the screen via two M3-Series mirror galvanometers (GSI Lumonics, Billerica, LA). This red spot was only briefly presented during $10 \mathrm{~ms}$, and we will thus refer to it as a "flash" [flash durations between 5 and $20 \mathrm{~ms}$ have been used successfully (Gellman and Fletcher 1992; Schlag et al. 1990)]. A dedicated real-time com- puter running LabViewRT (National Instruments, Austin, TX) software controlled position, velocity, and illumination of both targets. We recorded the movements of one eye using the scleral search coil technique (Skalar Medical BV, Delft, The Netherlands) (Collewijn et al. 1975; Robinson 1963).

\section{Paradigm}

All recording sessions were composed of blocks of 40 trials each. Data acquisition started with two blocks of fixation control (FIX) trials followed by a varying number of blocks of test trials, such that a total recording duration of $30 \mathrm{~min}$ was not exceeded. Flashes were presented during fixation (control FIX), during ongoing smooth pursuit ("flash during ramp" FDR test) or after the pursuit ramp offset ("flash after ramp" FAR control).

Fixation control (FIX) trials started with a green central fixation spot. At a random time 500-1,000 ms after the trial began, a $10-\mathrm{ms}$ red flash was presented at a random position between $-10^{\circ}$ and $+10^{\circ}$ horizontally and vertically. Subjects were asked to look at the memorized target position as soon as the flash appeared and to fixate this position until the end of the trial. They had to redirect gaze to the memorized target position even though the fixation spot remained illuminated. One thousand milliseconds after the flash, the green fixation spot was extinguished for $500 \mathrm{~ms}$ to indicate the end of the trial.

Test trials started with a 500-ms initial fixation period (green target) at $20^{\circ}$ eccentricity (Fig. $1 A, \mathrm{IF}$ ) in a random direction around the straight-ahead position. The initial fixation point was thus located at a random position on a $20^{\circ}$ circle around the straight-ahead direction (Fig. 1A, - -). Then the green spot performed a step away from the center of the screen and a ramp movement (Fig. 1A, ramp) back toward the center of the screen. The size of the step was calculated in such a way that the target crossed the initial fixation point after 200 ms. This step was introduced to reduce the probability of occurrence of a catch-up saccade during pursuit initiation (Rashbass 1961). The ramp velocity varied randomly between 10 and $40 \%$ s. A 10 -ms red flash (Fig. 1A, flash) was presented at a random time between 500 and $1,500 \mathrm{~ms}$ after the ramp movement onset. The flash position was randomly chosen in a squared $\pm 10^{\circ}$ (horizontal and vertical) window around the actual pursuit ramp position. The ramp movement continued until the end of the trial. All trials lasted for $3 \mathrm{~s}$. Subjects were instructed to follow the green pursuit target and to look at the memorized position of the flash as soon as they saw the flash.

In addition to the test trials, all subjects performed "flash after ramp" control (FAR) trials. FAR controls were similar to test trials, but the green pursuit ramp target was extinguished at a random time between 500 and 1,000 $\mathrm{ms}$ after the ramp movement onset and remained extinguished until the end of the trial. At a random time 0-500 ms after the pursuit ramp extinction, a red flash was presented in $\mathrm{a} \pm 10^{\circ}$ window (horizontally and vertically) around the extrapolated ramp position. We chose to introduce this random extinction period to obtain different patterns of eye velocity after the flash presentation. Beside this, all stimulus parameters and subject's instructions remained the same as for test trials.

\section{Data acquisition and analysis}

Two NI-PXI-6025E data-acquisition boards (National Instruments, Austin, TX) sampled the position of one eye and both targets (horizontally and vertically) at $500 \mathrm{~Hz}$. Collected data were stored on a hard disk for off-line analysis with Matlab scripts (Mathworks, Natick, MA). Position signals were low-pass filtered using a zerophase digital filter (autoregressive forward-backward filter; cutoff frequency: $50 \mathrm{~Hz}$ ). Velocity and acceleration were derived from position signals using a weighted central difference algorithm on a \pm 10 -ms interval. The cutoff frequency of the derivative filter was $33 \mathrm{~Hz}$. 
A
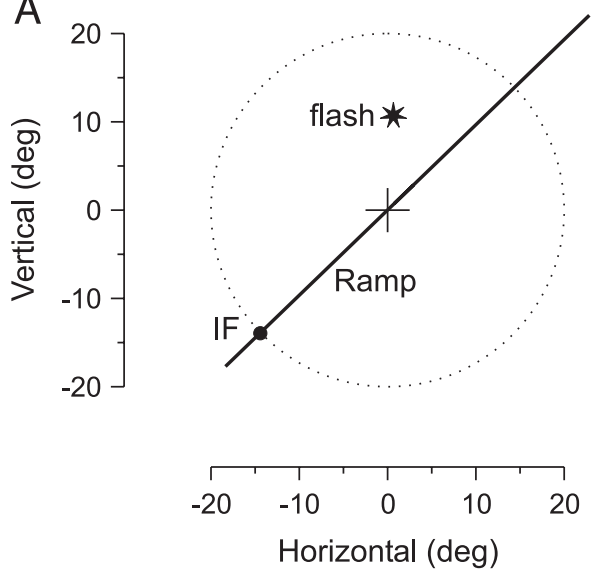

B

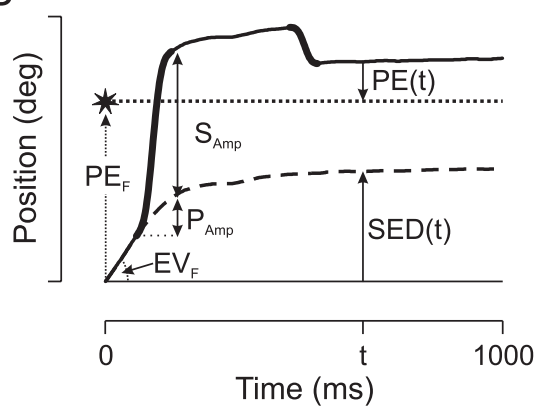

C

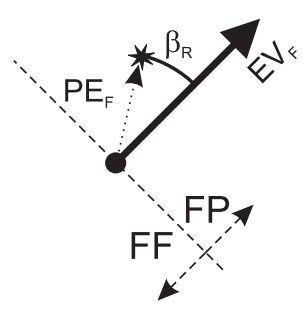

FIG. 1. Experimental paradigm and data analysis. A: test trials paradigm. The initial fixation point $(\mathrm{O}, \mathrm{IF})$, the pursuit ramp and the flash $(*)$ are represented. - - -, the possible positions of the initial fixation point. $B$ : extracted parameters. At the time of the flash (*; - - -, the memorized flash position), position error $\left(\mathrm{PE}_{\mathrm{F}}\right)$ and eye $\left(-\right.$, saccades in bold) velocity $\left(\mathrm{EV}_{\mathrm{F}}\right)$ were sampled. The $1 \mathrm{st}$ saccade amplitude was divided into the purely saccadic $\left(\mathrm{S}_{\mathrm{Amp}}\right)$ and the smooth $\left(\mathrm{P}_{\mathrm{Amp}}\right)$ component. Position error $(\mathrm{PE}(\mathrm{t}))$ and smooth eye displacement $[\mathrm{SED}(\mathrm{t})]$ are also represented. $C$ : direction of smooth pursuit with respect to the location of the flash. $\beta_{\mathrm{R}}$ is the angle between position error $\left(\mathrm{PE}_{\mathrm{F}}\right)$ and eye velocity $\left(\mathrm{EV}_{\mathrm{F}}\right)$ at the moment of the flash. The visual field was divided into foveofugal (FF) and foveopetal (FP) hemifields. See text for more details.

All trials were aligned on flash onset. Figure $1 B$ illustrates an example in one dimension, starting from the moment of the flash onset (time: $0 \mathrm{~ms}$ ) until 1,000 ms after the flash. The instantaneous smooth eye displacement at time $t$ was defined as the integral of the smooth eye velocity $\operatorname{EV}_{\mathrm{S}}(t)$ over time, starting at the moment of the flash $\left[\mathrm{SED}(t)=\int_{0}^{t} \mathrm{EV}_{\mathrm{s}}\left(t^{\prime}\right) \mathrm{d} t^{\prime}\right]$. The smooth eye velocity $\mathrm{EV}_{\mathrm{S}}(t)$ was obtained by removing saccades from the velocity trace. Saccades were detected using a $500 \% \mathrm{~s}^{2}$ acceleration threshold. We then measured the eye velocity before and after the saccades and interpolated linearly between these values to obtain an estimation of the smooth eye velocity during saccades (see METHODS section of de Brouwer et al. 2002 for more details).

To analyze the first saccade programming, the saccadic amplitude had to be corrected for the contribution of the smooth-pursuit system. It has indeed been shown for horizontal eye movements that the smooth-pursuit system does not pause during saccades and thus has a significant contribution to the measured saccade amplitude (de Brouwer et al. 2001, 2002). Therefore to examine the output of the saccadic system in isolation, the measured value of the saccade amplitude (AMP) has to be corrected by an estimate of the smooth-pursuit contribution $P_{\text {Amp }}$ (see Fig. $1 B$ ). The corrected saccade amplitude is then $S_{\mathrm{Amp}}=\mathrm{AMP}-P_{\mathrm{Amp}}$. The smooth-pursuit contribution $P_{\mathrm{Amp}}$ is calculated by multiplying the saccade duration $S_{\text {Dur }}$ with the mean value of the eye velocity before and after the saccade (de Brouwer et al. 2001, 2002; Keller and Johnsen 1990; Smeets and Bekkering 2000). Here, we performed the same correction of the saccade amplitude for 2-D saccades. We tested the validity of the correction for each subject individually on the main sequence relationship between saccade duration $S_{\text {Dur }}$ and vectorial amplitude AMP. For all subjects, the corrected vectorial saccade amplitude $S_{\text {Amp }}$ was significantly better correlated to $S_{\text {Dur }}$ than the uncorrected amplitude AMP ( $t$-test, $P<0.01$ ). We thus validated the previously proposed method of the saccade amplitude correction for 2-D data. All analyses in this paper will thus use the corrected saccade amplitude $S_{\text {Amp }}$.

For our analysis, we measured different parameters as illustrated in Fig. $1 B$. The range of these parameters is provided in Table 1. At the moment of the flash, we measured the horizontal and vertical component of the position error $\mathrm{PE}_{\mathrm{F}}$ (= retinal error) and eye velocity $\mathrm{EV}_{\mathrm{F}}$ and also the smooth-pursuit gain $\left(\right.$ gain $\left._{\mathrm{SP}, \mathrm{F}}\right)$. Following the abovedescribed procedure, the total saccade amplitude AMP was divided into a purely saccadic component $S_{\mathrm{Amp}}$ and a smooth-pursuit contribution $P_{\text {Amp }}$. Position error $\mathrm{PE}(t)$ and smooth eye displacement $\operatorname{SED}(t)$ were measured continuously until $1,000 \mathrm{~ms}$ after the flash. For the analysis of the saccade latency, we partitioned our data into two distinct subsets, i.e., foveofugal (FF) and foveopetal (FP) flashes (see Fig. 1C). In FP (FF) trials, the flash was presented ahead (behind) the actual eye position with respect to the direction of the eye trajectory. Thus as the terms "foveofugal" and "foveopetal" intuitively suggest, the eye motion made the fovea to move either away (foveofugal) or toward (foveopetal) the target at the moment of the flash presentation. It should be noted that a FP flash could evoke both onward and backward saccades (with respect to the smooth eye movement direction, see typical trials in Fig. 2). We also calculated the angle $\beta_{\mathrm{R}}$ between $\mathrm{EV}_{\mathrm{F}}$ and the position error $\mathrm{PE}_{\mathrm{F}}$ at the moment of the flash.

TABLE 1. Measured parameters

\begin{tabular}{|c|c|c|c|}
\hline Parameter & Component & Mean \pm SD & Median [25..75]\% \\
\hline \multicolumn{4}{|c|}{$\begin{array}{l}\text { Parameters at the } \\
\text { moment of the flash }\end{array}$} \\
\hline \multirow[t]{2}{*}{$\left|\mathrm{PE}_{\mathrm{F}}\right|\left(^{\circ}\right)$} & $\mathrm{X}$ & $5.447 \pm 3.478$ & $5.258[2.644 . .7 .878]$ \\
\hline & $\mathrm{Y}$ & $5.531 \pm 3.619$ & $5.253[2.584 . .7 .997]$ \\
\hline \multirow[t]{2}{*}{$\left|\mathrm{EV}_{\mathrm{F}}\right|(\% / \mathrm{s})$} & $\mathrm{X}$ & $10.819 \pm 7.718$ & $9.395[4.687 . .15 .231]$ \\
\hline & $\mathrm{Y}$ & $9.201 \pm 6.459$ & $8.077[4.220 . .12 .853]$ \\
\hline $\operatorname{Gain}_{\mathrm{SP}, \mathrm{F}}()$. & & $0.678 \pm 0.256$ & $0.708[0.500 . .0 .865]$ \\
\hline \multicolumn{4}{|l|}{$\begin{array}{r}\text { Saccade-related } \\
\text { parameters }\end{array}$} \\
\hline \multirow[t]{2}{*}{$\left|\mathrm{S}_{\mathrm{Amp}}\right|^{*}\left(^{\circ}\right)$} & $\mathrm{X}$ & $5.057 \pm 3.524$ & $4.506[2.187 . .7 .348]$ \\
\hline & $\mathrm{Y}$ & $4.573 \pm 3.602$ & $3.770[1.670 . .6 .716]$ \\
\hline \multirow[t]{2}{*}{ gain $_{\mathrm{S}}()}$. & $\mathrm{X}$ & $0.908 \pm 0.371$ & $0.898[0.683 . .1 .117]$ \\
\hline & Y & $0.805 \pm 0.388$ & $0.791[0.546 . .1 .024]$ \\
\hline \multirow{2}{*}{$\left|\mathrm{SED}_{\mathrm{S}, \mathrm{beg}}\right|\left(^{\circ}\right)$} & $\mathrm{X}$ & $1.992 \pm 1.848$ & $1.440[0.661 . .2 .771]$ \\
\hline & $\mathrm{Y}$ & $1.669 \pm 1.472$ & $1.239[0.617 . .2 .268]$ \\
\hline \multirow[t]{2}{*}{$\left|\mathrm{SED}_{\mathrm{S}, \text { end }}\right|\left(^{\circ}\right)$} & $\mathrm{X}$ & $2.568 \pm 2.166$ & $2.010[0.974 . .3 .632]$ \\
\hline & Y & $2.168 \pm 1.724$ & $1.742[0.926 . .2 .989]$ \\
\hline \multicolumn{4}{|l|}{$\begin{array}{c}\text { Final orientation } \\
\text { parameters }\end{array}$} \\
\hline \multirow[t]{2}{*}{$\left|\mathrm{PE}_{\text {end }}\right|\left(^{\circ}\right)$} & $\mathrm{X}$ & $2.319 \pm 2.030$ & $1.778[0.816 . .3 .311]$ \\
\hline & $\mathrm{Y}$ & $2.156 \pm 1.889$ & $1.684[0.817 . .2 .912]$ \\
\hline \multirow[t]{2}{*}{$\left|\mathrm{SED}_{\text {end }}\right|\left(^{\circ}\right)$} & $\mathrm{X}$ & $3.217 \pm 2.640$ & $2.595[1.219 . .4 .503]$ \\
\hline & $\mathrm{Y}$ & $2.851 \pm 2.256$ & $2.329[1.165 . .4 .012]$ \\
\hline
\end{tabular}

$n=4,464$ trials. 

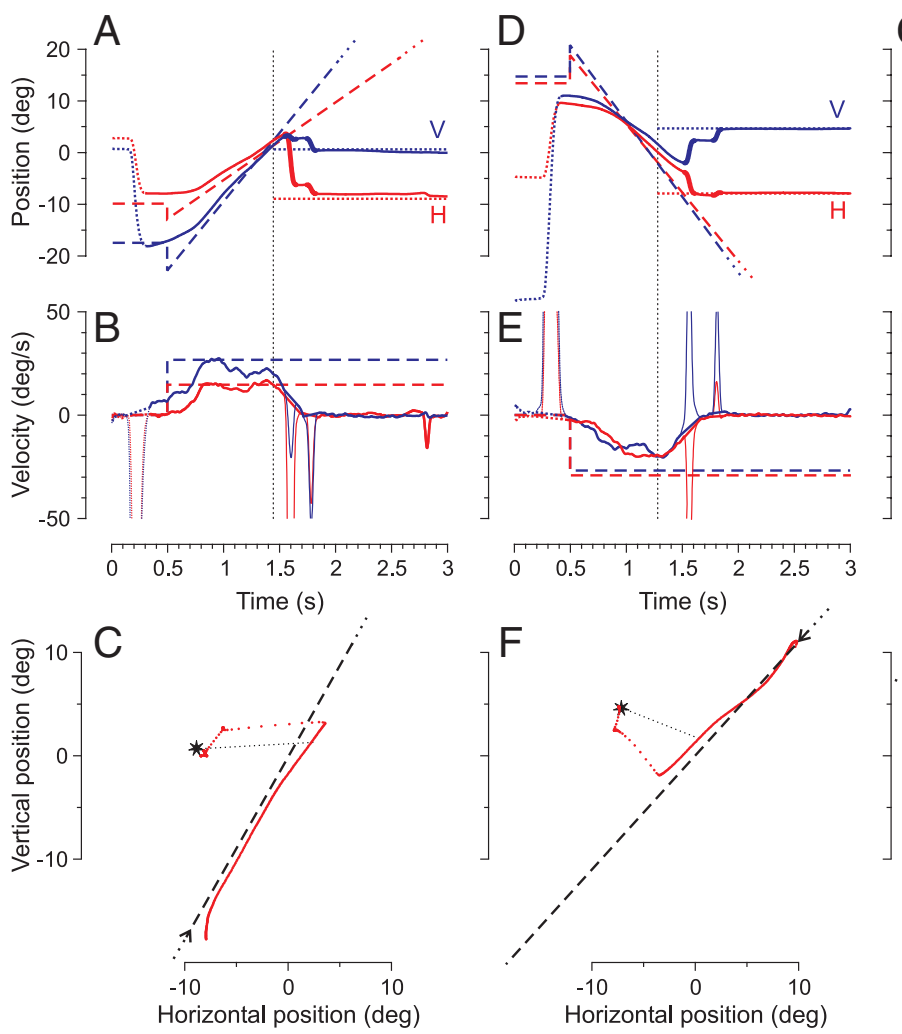

We performed our statistical analyses either using Statistica (StatSoft, Tulsa, OK) or Matlab (Mathworks) programs. For the presentation and description of our results, we used the classical expression of the regression coefficient $\mathrm{R}$ (and corresponding $P$ values for significance) to provide an indication of the goodness-of-fit. This was the case for linear regressions as well as for nonlinear fitting.

\section{RES U L T S}

We recorded a total of 5,855 test trials. All trials were visually inspected. We discarded trials with saccades occurring around the moment of the flash $\leq 65 \mathrm{~ms}$ after the flash onset $(n=956)$ and trials where subjects could not localize correctly the flashed target (final error $>10^{\circ}$ ) or did not trigger any saccade $(n=435)$. The total number of valid trials we used in our analyses was thus $n=4,464(\sim 76 \%)$. We also recorded a total of 1,957 control FIX trials and 5,919 control FAR trials, of which 1,542 ( 79\%) and 4,402 ( 74\%), respectively, were valid. Subjects reported that they did not have any difficulties in performing the experimental tasks.

Figure 2 shows three trials with a typical short-latency $(A-C)$, long-latency $(D-F)$, and very-long-latency $(G-I)$ first saccade, respectively. We were only interested in saccades that occurred after the onset of the flash (dotted vertical line in the six top panels of Fig. 2). The first orientation saccade in Fig. 2, $A-C$, had a latency of $104 \mathrm{~ms}$ with respect to the flash and was almost parallel to the position error vector at the moment of the flash $\mathrm{PE}_{\mathrm{F}}$ (= retinal error; dotted line in Fig. $2 C$ ). It seems that this saccade did not take into account the smooth eye movement during the latency period. However, a second saccade was triggered and compensated for the remaining error. A different behavior is shown in the second typical trial, in Fig. 2, $D-F$, where the first saccade toward the flash had a latency of $238 \mathrm{~ms}$ and was not parallel to $\mathrm{PE}_{\mathrm{F}}$ vector (Fig. $2 F$ ). Indeed,
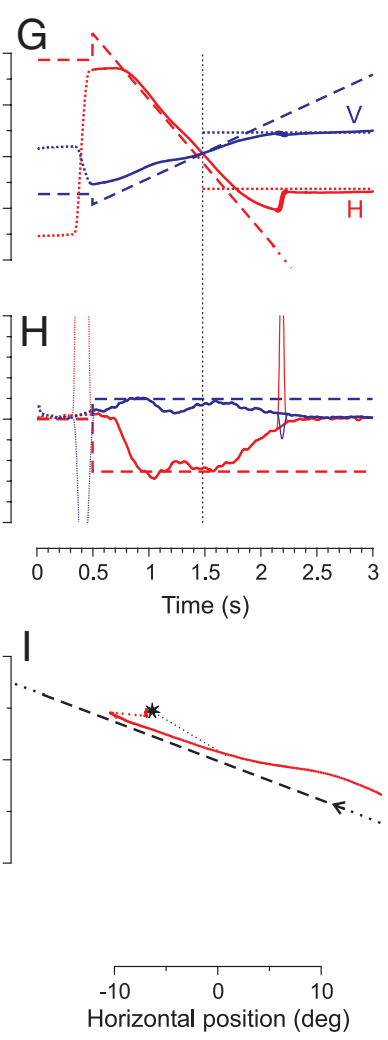

FIG. 2. Typical trials. Three typical trials are shown. $A-C$ : a short-latency (104 ms) trial; $D-F$ : a long-latency (238 ms) trial; and $G-H$ : very-long-latency (674 ms) trial. $A, D$, $G$ : position vs. time representation of the pursuit target (dashed lines), the flash (horizontal dotted lines stand for the memorized flash position) and the movement of 1 eye (solid lines) separately for horizontal (red, H) and vertical (blue, V) components. Relevant saccades are represented with bold lines. The vertical dotted line indicates when the flash was presented. $B, E, H$ : velocity vs. time representation of the trial. Saccades are represented with thin lines; other conventions are the same as in $A, D$, and $G . C, F, I$ : vertical vs. horizontal representation of the trial. The dashed line represents the pursuit ramp target and the arrow indicates the movement direction. The eye position is represented with a red dot every $6 \mathrm{~ms}$. When the dots are separated, this indicates a fast (saccadic) eye movement; otherwise the movement is smooth. The flash (star) is connected to the eye trace by a thin dotted line that indicates where the eye was at the moment of the flash $\left(=\mathrm{PE}_{\mathrm{F}}\right)$.

this saccade seemed to take into account the fact that the eye was moving during the latency period. However, a second saccade was still needed to correct for the remaining error. Figure 2, $G-I$, shows an extreme case where the first saccade was triggered very late (latency: $674 \mathrm{~ms}$ ). This example shows an almost perfect compensation for the smooth eye displacement that took place during the latency period. Remarkably, although the horizontal retinal position error at the moment of the flash was negative, the horizontal saccade amplitude was positive. These three trials in Fig. 2 illustrate the influence of latency on the characteristics of the first saccade. The programming of short latency saccades appears to be directed to the retinal position of the flash whereas there is a bias toward the spatial location of the flash when saccade latency increases.

\section{Programming of first saccade}

Typical trials in Fig. 2 seemed to indicate that short- and long-latency saccades were not programmed in the same way. Short-latency saccades (see Fig. 2, A-C) appeared to be parallel to the vector of retinal position error at the moment of the flash, whereas long-latency saccades (see Fig. 2, $D-I$ ) indicate that extra-retinal signals about the ongoing eye movement during the latency period of the saccade could also influence its programming. Long-latency saccades would thus be spatially more accurate than the retinal short-latency saccades. Figure 3 shows a comparison of the retinal versus the spatial saccadic programming hypothesis as a function of saccade latency. Figure 3 shows scatter plots of the first saccade direction for the retinal and spatial error hypothesis, for short $(<150 \mathrm{~ms})$ and long ( $>300 \mathrm{~ms}$ )-latency trials separately. This confirmed the tendency shown in our example trials (Fig. 2), i.e., shortlatency saccades were better described by the retinal error 

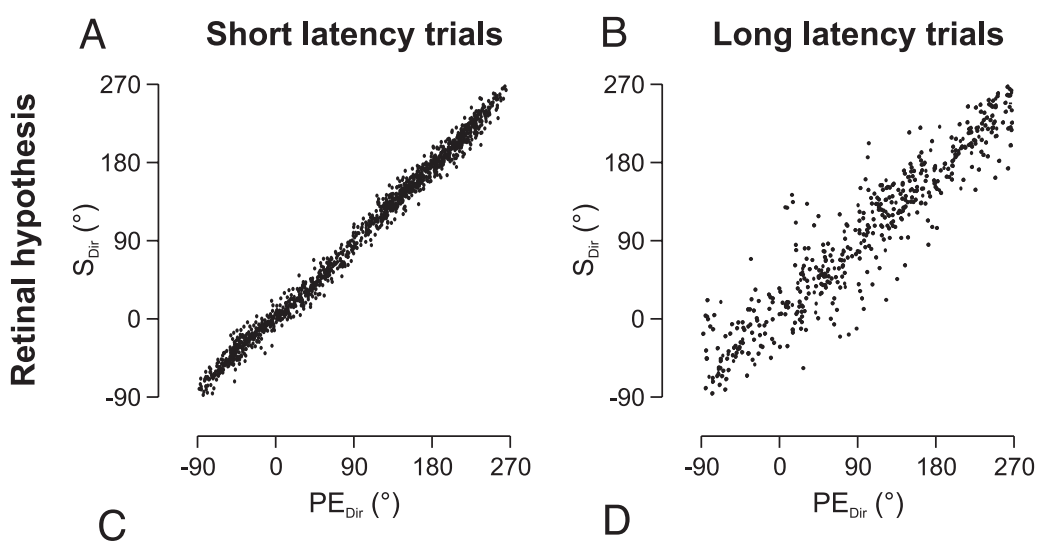

FIG. 3. Retinal vs. spatial saccade programming. Scatter plots of raw data for the 1st saccade direction $\left(S_{\text {Dir }}\right)$ as a function of the direction of the position error $\left(\mathrm{PE}_{\mathrm{Dir}}\right)$. The retinal error hypothesis $(A$ and $B)$ is compared with the spatial error hypothesis $(C$
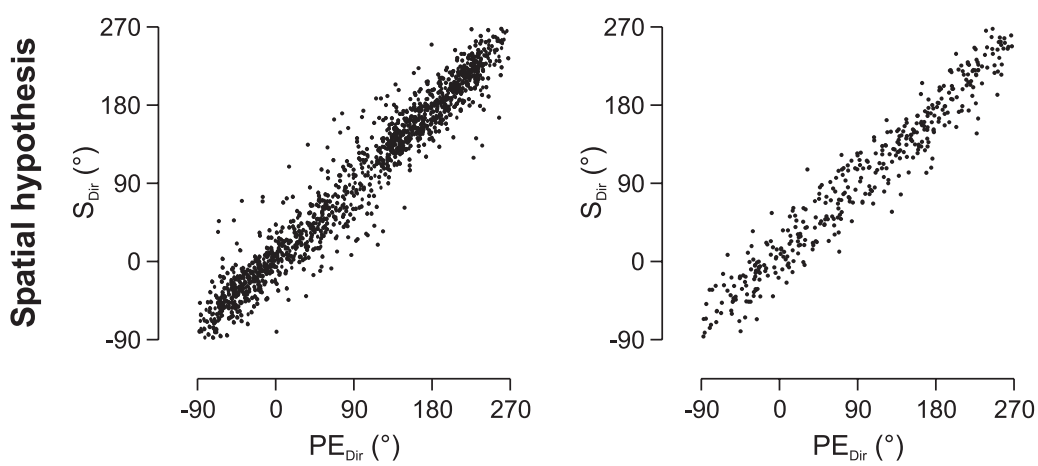
and $D$ ) separately for short-latency trials (latency $<150 \mathrm{~ms}, A$ and $C$ ) and long-latency trials (latency $>300 \mathrm{~ms}, B$ and $D$ ).

hypothesis, whereas long-latency saccades were spatially more accurate. A qualitatively and quantitatively very similar behavior was observed for FAR control trials (data not shown).

To analyze the transition between the retinal and spatial programming of the first orientation saccade, we developed a smooth eye displacement compensation index (CI). This index varies from zero (retinal error hypothesis) to one (spatial saccade programming) and is calculated as follows

$$
\mathrm{CI}=1+\frac{\mathrm{PE}_{\|}}{\mathrm{SED}}
$$

Position error $\left(\mathrm{PE}_{\|}\right)$and smooth eye displacement (SED) were measured in the direction of (and thus parallel to) smooth pursuit. Following $E q$. 1, if $\mathrm{PE}_{\|}=-\mathrm{SED}$, then the system did not compensate for SED and thus CI $=0$ (retinal programming). If the system does compensate for SED, then $\mathrm{PE}_{\|}=0$ and thus $\mathrm{CI}=1$ (spatial programming). Values for CI between 0 and 1 indicate the percentage of SED compensation of a saccade. Figure 4 shows the results of this analysis. Figure $4 A$ shows the distribution of the compensation index CI for short $(<150 \mathrm{~ms}$, 圆) and long $(>300 \mathrm{~ms}, \square)$ latency first saccades. In $B$, we represented the evolution of CI with saccade latency. This shows that short-latency saccades were $\sim 85 \%$ retinal and only $15 \%$ spatial. In contrast, the programming for longerlatency saccades converges $\sim 75 \%$ spatial coding, leaving a $25 \%$ retinal contribution to the saccadic programming. Furthermore, Fig. $4 C$ shows the evolution of the compensation index over time for each subject individually. This confirms the results from Fig. 3 indicating that short-latency saccades are programmed retinally, whereas there is a transition toward the spatial error hypothesis for longer saccade latencies.

To be sure that the retinal to spatial transition we observed was not due to some side-effect of saccade programming, we measured the saccadic gain orthogonal to the pursuit ramp

movement direction in Fig. 5. Because there was no SED in this orthogonal direction, the saccadic gain was a good measure of the movement's accuracy. As a result, there was neither a significant modulation of this saccadic gain for different latencies, nor a difference between test trials and FIX control trials (see Fig. 5). It should be mentioned that the scatter in Fig. 5 was essentially due to small position errors.

\section{Saccadic latency distribution}

We plotted the first saccade latency histogram for FDR trials, FAR controls, and FIX controls in Fig. 6, $A-C$, respectively. One can easily identify two modes in the latency distribution. To further characterize the two modes of these histograms, we fitted a double-recinormal distribution to our data. The double-recinormal distribution for the latencies has the following expression

$$
\frac{1}{T_{\text {lat }}}=A_{1} \cdot \operatorname{gauss}\left(\mu_{1}, \sigma_{1}\right)+A_{2} \cdot \operatorname{gauss}\left(\mu_{2}, \sigma_{2}\right)
$$

The inverse of the saccade latency $T_{\text {lat }}$ was thus fitted by two independent Gaussians. This is equivalent to the hypothesis of two separate and noninteracting decision processes of the LATER type (Carpenter and Williams 1995). Indeed, the LATER model states that the inverse of saccade latency is proportional to the rate of rise of a decision signal divided by the decision threshold. The particularity of the LATER model is that the decision signal is assumed to rise linearly with a normally distributed rate of rise. We essentially chose this double-recinormal fit function because it described well our data and allowed us to quantify with very few parameters the entire latency distribution. However, to justify the use of this particular probability density function, we performed a k-fold cross-validation applying the Kolmogorov-Smirnov statistical 

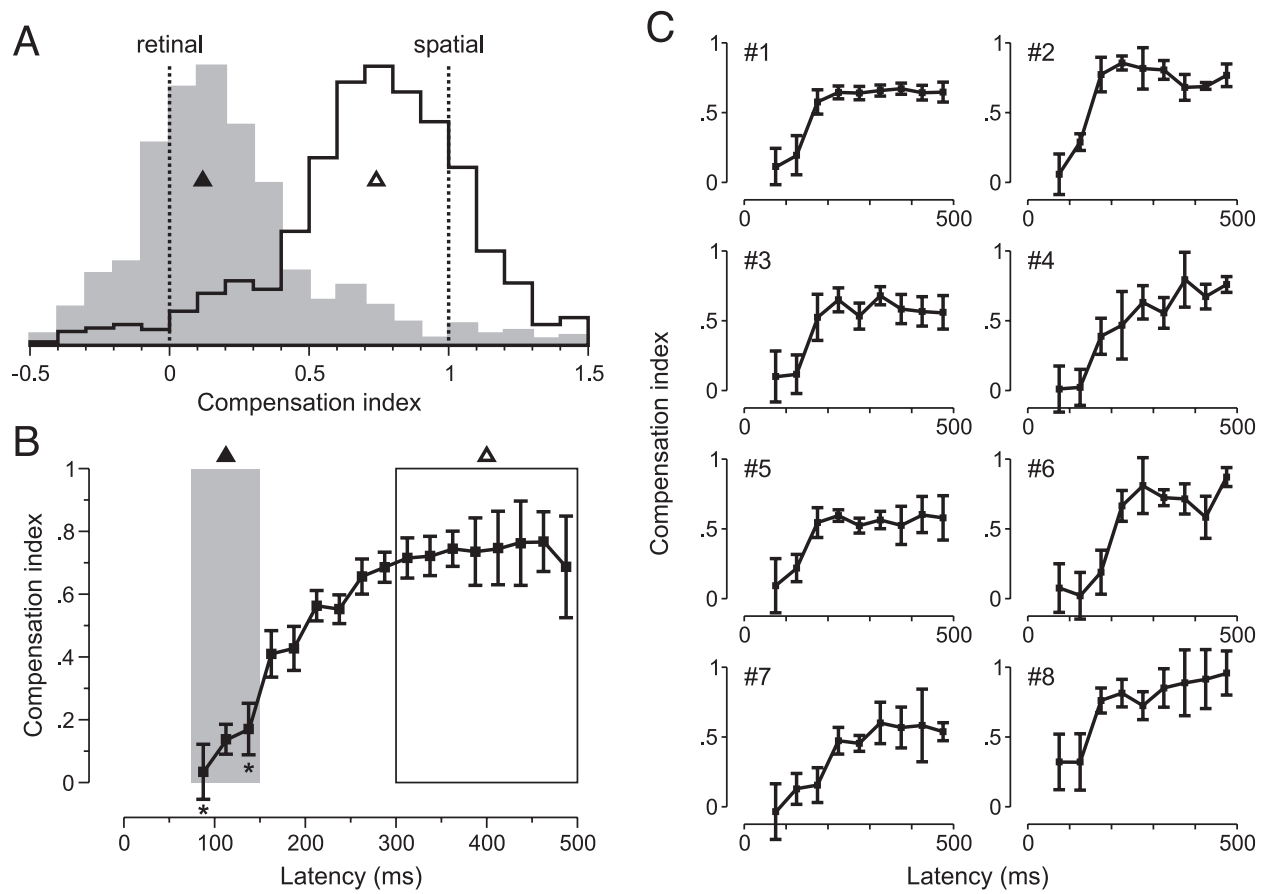

FIG. 4. First saccade compensation index for smooth eye movements. A: histograms for the distribution of the compensation index as calculated in Eq. 1 for short-latency trials (latency $<150 \mathrm{~ms}, \square$ ) and long-latency trials (latency $>300 \mathrm{~ms}, \square$ ). A 0 compensation index corresponds to retinal saccade programming, whereas a unitary compensation index corresponds to spatially accurate saccades. $\Delta$ and $\Delta$ refer to $B$. Histograms are normalized in amplitude. $B$ : evolution of the compensation index for different saccade latencies. and whiskers indicate means $\pm \mathrm{SE}$ (25-ms bins). *, when the means are not significantly different from 0 ( $t$-test, $P>$ $0.05)$. with $\mathbf{\Delta}$ : corresponds to the data represented in $\square$ of $A$. $\square$ with $\Delta$, the data range of $\square$ in $A$. $C$ : evolution of the compensation index for different saccade latencies individually for each of the 8 subjects $(50-\mathrm{ms}$ bins).

one-sample distribution test. Therefore we used a random subset of $75 \%$ of our data to estimate the fit parameters of Eq. 2 by means of standard least-square data fitting using the Gauss-Newton method. Afterward, we performed a Kolmogorov-Smirnov analysis to test if the remaining $25 \%$ of our data were distributed identically to the previously identified distribution. This procedure was performed $k=1,000$ times. As a result, we found an average $98.3 \%$ acceptance of the doublerecinormal probability density function hypothesis $(5 \%$ significance level).

To estimate the fit parameters, we applied the same leastsquare data fitting as used above. As a result, we obtained the means and SDs (inverse time scale) for the best fit of Eq. 2 on the histograms. Hereafter, we will provide values for $\mathrm{m}_{\mathrm{i}}=1 / \mu_{\mathrm{i}}$ (location of the maximum) and $s_{\mathrm{i}}=\frac{1}{2} \cdot\left(\frac{1}{\mu_{\mathrm{i}}-\sigma_{\mathrm{i}}}+\frac{1}{\mu_{\mathrm{i}}+\sigma_{\mathrm{i}}}\right)$ (estimated scatter), which are in the real-time domain and thus intuitively easier to interpret. Maxima \pm scatter were $115 \pm 40$ and $225 \pm 41 \mathrm{~ms}$, respectively, for both modes of the doublerecinormal fit (dotted line) on the latency histogram of FDR trials in Fig. $6 A, 110 \pm 35$ and $222 \pm 25 \mathrm{~ms}$ for FAR trials in Fig. $6 B$, and $134 \pm 36$ and $220 \pm 21 \mathrm{~ms}$ for FIX controls in Fig. $6 C$. Note, that there were also two distinct latency modes for both FAR and FIX control trials. However, in the FAR control situation, the less frequent second mode might be due to the fact that the flashed stimulus did not compete any more with the pursuit ramp target. Interestingly, the minimum between the two modes in Fig. $6 A$ was located $\sim 175 \mathrm{~ms}$, which was approximately the time needed for the extraretinal smooth eye movement signal to be taken into account for the saccade programming (see CI in Fig. 4). The individual latency histograms of FDR trials for each subject in Fig. $6 D$ demonstrate that both latency modes were present in each subject, although with different proportions and slightly different locations of the maxima.

Previous studies showed that there is an inhibition of saccade initiation to previously attended positions (Klein 2000) and that there is a directional asymmetry of saccade latency during smooth-pursuit eye movements (Kanai et al. 2003; Tanaka et al. 1998), i.e., saccades executed in the same direction as pursuit have shorter latencies than saccades in the opposite direction. All these experiments describe saccade latencies to visible stationary or moving targets. Here we investigated whether a similar behavior could also be observed for memory-guided saccades to briefly flashed targets. Furthermore, previous studies that analyzed smooth-pursuit-related directional differences in saccade latency used only horizontal stimuli and eye movements. Here, our 2-D paradigm will allow us to test saccadic latencies for different positions of the flash with respect to the smooth-pursuit direction.

To address the question of a possible directional asymmetry of saccade latencies, we separated our data into foveofugal (FF) and foveopetal (FP) trials (see METHODS section, Fig. 1C). Figure 7, $A$ and $C$, shows the latency distributions of FF (圆, - - ) and FP $(\square, \cdots)$ data separately for

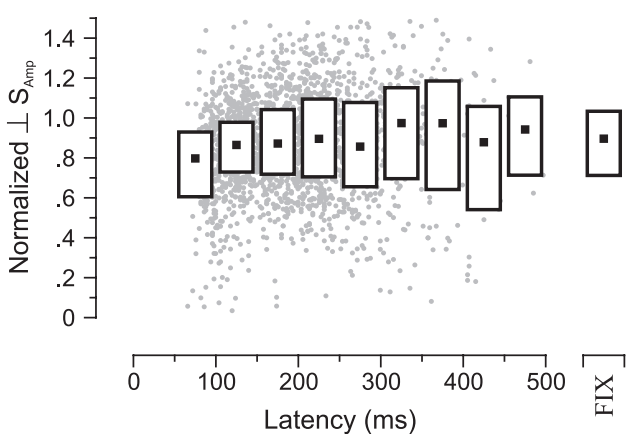

FIG. 5. Saccade accuracy. The normalized saccade amplitude perpendicular to the initial ramp movement direction was used as an indicator for the subject's saccade accuracy. The latency-dependent computations of this median saccade gains were compared with the fixation (FIX) control situation. $\odot$, individual saccades; $\mathbf{\square}$ and $\square$, the median and quartiles. In addition, individual tests for each subject showed no significant latency dependence of the saccade accuracy ( $t$-test, $P>0.1$ ). 


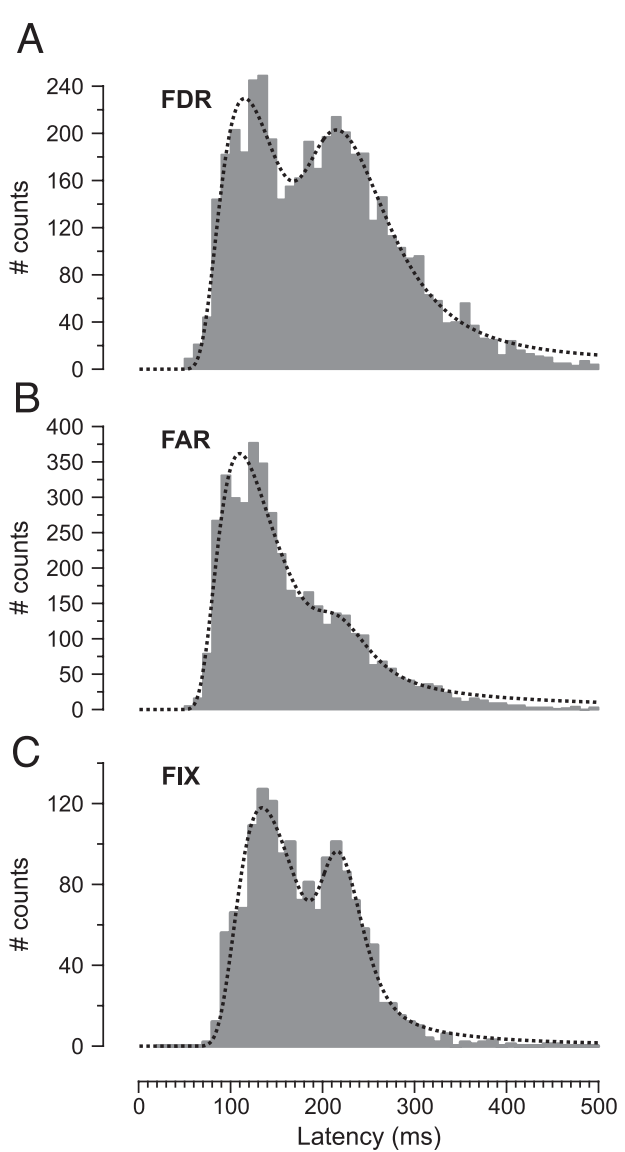

D
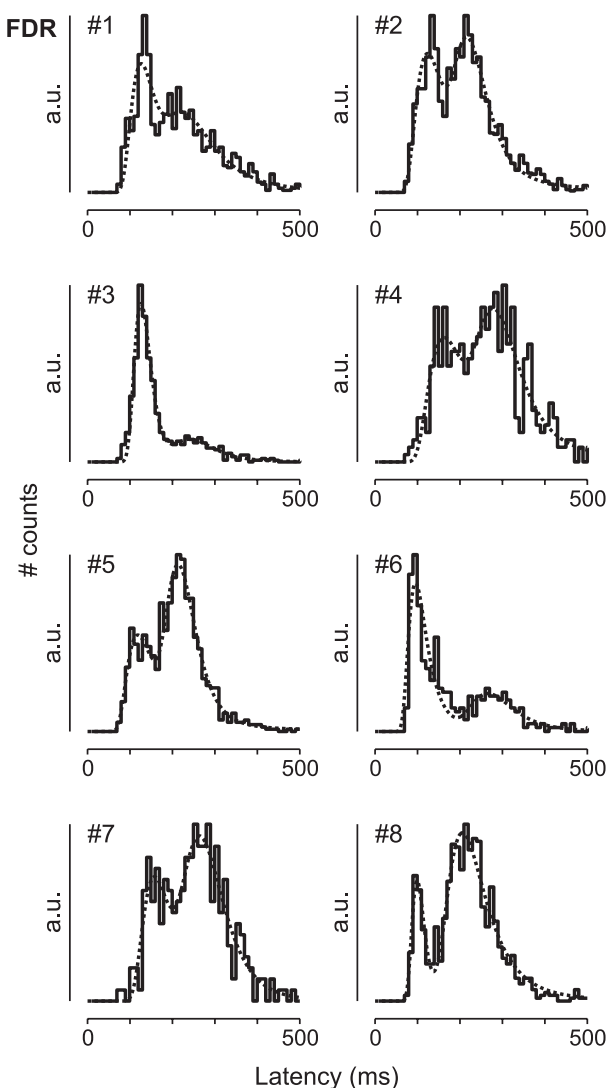

FIG. 6. First saccade latency. A: latency histogram for flash during ramp (FDR) trials $(n=4,464)$. The dotted line represents a double-recinormal fit function with maxima at 115 and $225 \mathrm{~ms}$. B: latency histogram for flash after ramp (FAR) control trials $(n=$ 4,402). The double-recinormal fit function has maxima at 110 and $222 \mathrm{~ms}$. $C$ : latency distribution for FIX control trials. Fitted distribution maxima are at 134 and $220 \mathrm{~ms}$. $D$ : individual histograms for the 1st saccade latency distribution of all 8 subjects in the case of FDR trials. The fitted distribution maxima varied between 96 and $163 \mathrm{~ms}$ for the $1 \mathrm{st}$ latency mode and between 207 and $286 \mathrm{~ms}$ for the 2 nd mode.
FDR and FAR trials. Interestingly, the relative importance of the short- and long-latency modes changed between FP and FF trials, whereas their location was approximately constant. FP trials contained more short-latency than long-latency saccades, whereas the opposite was the case for FF trials. Thus the mean latencies for saccades to the FF and FP hemifield were 214 and $191 \mathrm{~ms}$, respectively for FDR trials (Fig. 7A) and 158 and 172 ms, respectively for FAR controls (Fig. 7C). The difference between both means was highly significant $(t$-test, $P<0.0001)$ in both cases. Note that the FP and FF data sets were slightly different in their total number of trials; this was due to an asymmetry in the paradigm. Therefore we also tested the FP/FF hemifield difference for a subset of our data with identical properties (we used the same range and distribution of $\mathrm{PE}_{\mathrm{F}}$ ) for $\mathrm{FP}$ and $\mathrm{FF}$ and found no difference with the abovereported results. On average, the latency of FF saccades was larger, but they were spatially more accurate when compared with FP saccades.

Our 2-D paradigm allowed us to go one step further and to ask for the first time whether the asymmetry in saccade latencies reported in Fig. 7, $A$ and $C$, was due to a pursuit related focus of attention or whether it might be the result of an inhibitory hemifield effect. Therefore we present in Fig. 7, $B$ and $D$, polar plots of mean saccade latencies depending on the angle $\beta_{\mathrm{R}}$ between the flash position and the pursuit eyemovement direction at the moment of the flash (see METHODS section, Fig. $1 C$ ). It can be easily observed that almost all mean latencies within the same hemifield had the same values and that there was a relatively sharp transition between the FP and FF hemifields.
How did the system decide whether to rapidly trigger a short latency but inaccurate saccade or to wait longer and trigger a spatially more accurate saccade? We investigated a possible dependence of the first saccade latency on the main sensory parameters measured at the moment of the flash appearance, i.e., the position error $\mathrm{PE}_{\mathrm{F}}$ and eye velocity $\mathrm{EV}_{\mathrm{F}}$ at the moment of the flash. In addition, we tested other parameters, like the smooth-pursuit gain ( gain $_{\mathrm{SP}, \mathrm{F}}$ ) at the moment of the flash, the target velocity or the duration of ongoing smooth-pursuit eye movement, but the overall regression results were best using the above-mentioned sensory variables. This analysis was also motivated by previous findings that showed a dependence of the mean saccade latency on the distance between the eye and the target (Bell et al. 2000; Clark 1999; Hodgson 2002; Kalesnykas and Hallett 1994).

The position error $\mathrm{PE}_{\mathrm{F}}$ at the moment of the flash was the first sensory parameter that influenced the distribution of saccade latency. Figure $8 A$ shows the dependence of the first saccade latency on the distance $\mathrm{PE}_{\mathrm{F}}$ between the flash and the eye for FDR (black) and FAR (gray) data. Mean values and standard errors in Fig. 8A essentially indicated that for small position errors $\left(\mathrm{PE}_{\mathrm{F}}<5^{\circ}\right)$ the latency was larger than for larger $\mathrm{PE}_{\mathrm{F}}$. We separated our data into three categories depending on $\mathrm{PE}_{\mathrm{F}}$, i.e., small $\left(\mathrm{PE}_{\mathrm{F}}<5^{\circ}\right)$, medium $\left(5^{\circ}<\mathrm{PE}_{\mathrm{F}}<10^{\circ}\right)$ and large $\left(10^{\circ}<\mathrm{PE}_{\mathrm{F}}\right)$ values, and computed the latency histograms and double-recinormal fits in Fig. $8 \mathrm{~B}$. For small $\mathrm{PE}_{\mathrm{F}}$ values, the long latency mode of the histogram was more important than for larger $\mathrm{PE}_{\mathrm{F}}$ values. While the value of the location of the short-latency mode's maximum remained roughly constant, the 

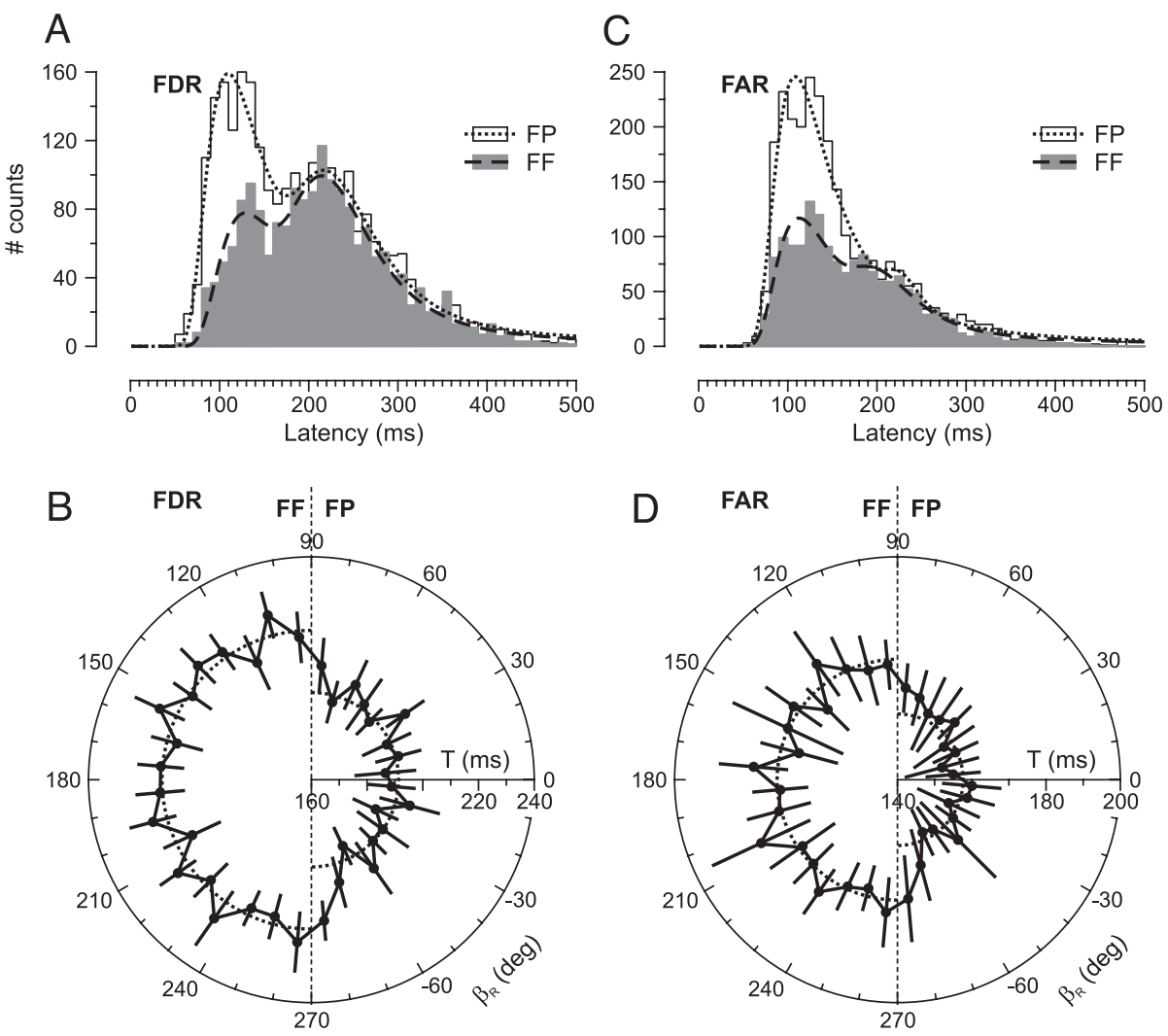

FIG. 7. Saccade latency dependence on direction. $A$ : The latency histogram for FDR trials as in Fig. $6 A$ but divided into 2 populations, i.e., foveofugal (FF, $\square, n=1,884$ ) and foveopetal (FP, $\square$, $n=2,580$ ) flash presentations. Maxima for the latency fit on the data were 129 and $223 \mathrm{~ms}$ for FF $(--)$ and 110 and $228 \mathrm{~ms}$ for FP $(\cdots)$ flashes. $B$ : polar plot of FDR saccade latencies as a function of the angle of flash appearance $\beta_{\mathrm{R}}$ relative to the smooth pursuit direction. $\beta_{\mathrm{R}}=0^{\circ}$ corresponds to a flash presented straight ahead in the direction of the eye movement. $\bigcirc$ and whiskers indicate mean \pm SE for the $10^{\circ}$-angle bins. $\cdots$, mean values of the FF (214 ms) and FP (191 ms) hemifield separately. The difference between both means was highly significant ( $t$-test, $P<0.0001)$. $C$ : as for $A$, the FAR latency histogram was divided into foveofugal (FF, $\square, n=1,768$ ) and foveopetal (FP, $\square, n=2,634$ ) flash presentations. FF maxima were at 113 and $207 \mathrm{~ms}$; FP maxima were at 109 and $228 \mathrm{~ms}$. $D$ : polar plot of saccade latencies as a function of the flash direction relative to the smooth pursuit direction. The same conventions as in $B$ apply. The mean values of FF and FP hemifield saccade latencies were 172 and $158 \mathrm{~ms}$, respectively. The difference between both means was highly significant $(t$-test, $P<0.0001)$.

longer latency mode of the distribution moved toward shorter latencies with increasing $\mathrm{PE}_{\mathrm{F}}$.

The second sensory parameter we found to influence the first saccade latency was the smooth eye velocity $E_{F}$ at the moment of the flash. Figure $8 C$ shows that the saccade latency depended approximately linearly on $\mathrm{EV}_{\mathrm{F}}$ for FDR (black) and FAR (gray) data. The regression equation on raw data of the linear fit (solid line) was $y=158 \mathrm{~ms}+2.48 \mathrm{~ms}^{*} x(R=0.183$, $P<0.0001)$ for FDR trials and $y=139 \mathrm{~ms}+2.80 \mathrm{~ms} * x(R=$ $0.226, P<0.0001$ ) for FAR controls. Similar to Fig. $8 B$, we subdivided our dataset into different ranges of the sensory parameter $\mathrm{EV}_{\mathrm{F}}$ (vertical dotted lines in Fig. 8C) and plotted the corresponding latency histograms and double-recinormal fits in Fig. $8 D$. Figure $8 D$ clearly demonstrates that the shift in mean saccade latency with higher $\mathrm{EV}_{\mathrm{F}}$ values was due to the increased relative importance of the long-latency mode. This effect was underlined by the fact that the location of the long-latency mode's maximum was slightly shifted toward larger values with increasing $\mathrm{EV}_{\mathrm{F}}$.

As a conclusion, our results concerning the influence of the sensory parameters on the first saccade latency revealed two distinct effects. First, large eye velocity $\left(\mathrm{EV}_{\mathrm{F}}\right)$ and small position error $\left(\mathrm{PE}_{\mathrm{F}}\right)$ increased the relative importance of the long-latency mode with respect to the shorter-latency mode. Second, we observed a shift of the long-latency mode toward larger values when eye velocity $\left(\mathrm{EV}_{\mathrm{F}}\right)$ was high and position error $\left(\mathrm{PE}_{\mathrm{F}}\right)$ was small. Performing the same analysis using both sensory parameters in combination increased this effect yielding to an absence of the first latency mode for combined small $\mathrm{PE}_{\mathrm{F}}$ and large $\mathrm{EV}_{\mathrm{F}}$, whereas long-latency saccades disappeared for a combination of large $\mathrm{PE}_{\mathrm{F}}$ and small $\mathrm{EV}_{\mathrm{F}}$ (data not shown).
We would like to emphasize that the hemifield difference between FP and FF flashes (see Fig. 7) was still present in all analyses concerning the sensory parameters in Fig. 8 (data not shown) and significant ( $t$-test, $P<0.01)$. We explicitly tested that our results were not an artifact of some combined parameter effect or even due to slight asymmetries of our dataset. As a result, we report here that both the FP/FF latency difference and the latency dependence on the sensory parameters at the time of the flash were consistent and unbiased effects. Furthermore, even though there were differences in the individual latency histograms when computed for each subject separately, all the above-described latency effects were present for all subjects.

\section{Time course of orientation}

After the first orientation saccade toward the memorized position of the flash, we usually observed one or more corrective saccades that brought the eye closer to the spatial position of the flash. This was the case irrespectively of whether the first saccade was triggered with short or longer latency (see typical trials in Fig. 2). The way in which the system reaches the memorized goal determined by a flash during smooth eye movements has previously been investigated for horizontal eye movements by Blohm et al. (2003), who showed that the saccadic system was able to compensate for smooth anticipatory eye movements with a certain delay. Here, we observed qualitatively the same behavior, i.e., some time was needed for the smooth eye displacement to be taken into account (see 1st saccade programming results).

As already mentioned, the purpose of secondary "catch-up" saccades was to compensate for the remaining uncorrected smooth eye displacement. Thus to analyze in more details the 

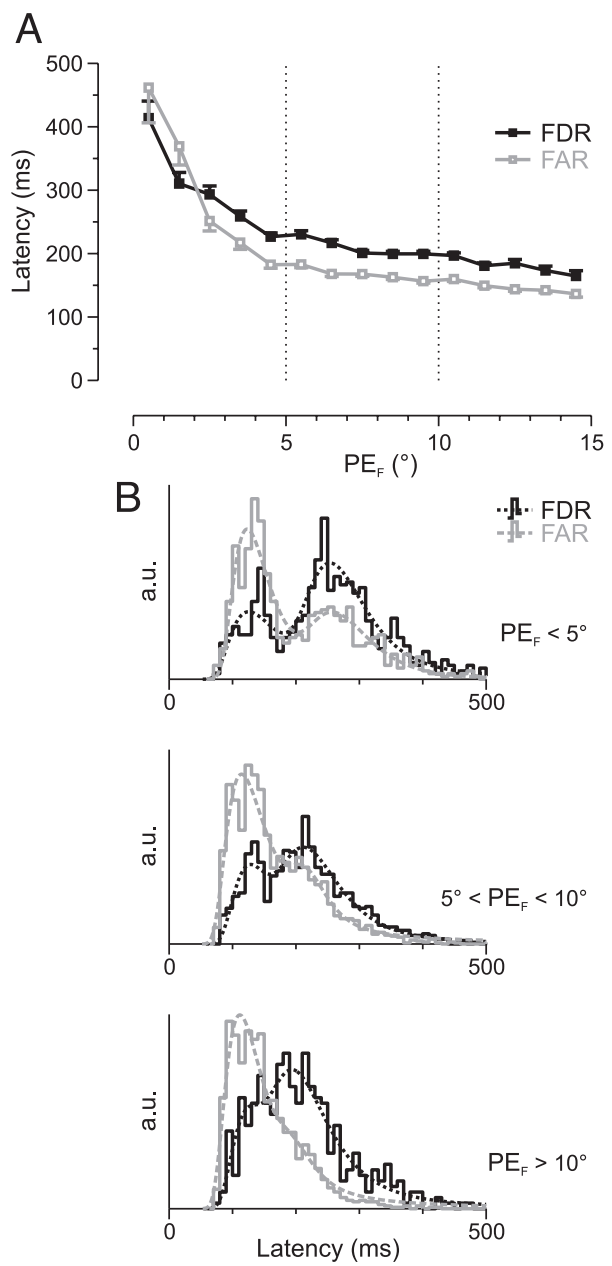

C
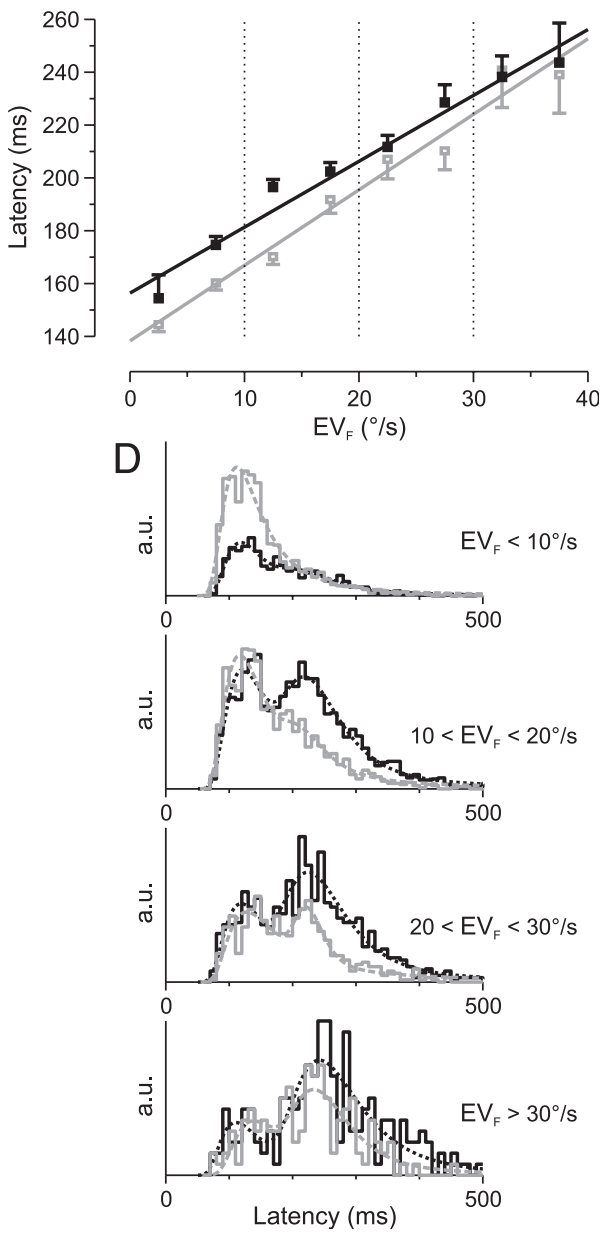

information about the total smooth eye displacement $\left(\mathrm{SED}_{\text {end }}\right)$. The compensation for the retinal flash position error $\mathrm{PE}_{\mathrm{F}}$ was 98.7\% (subject variability: $80.1-121.1 \%$ ) horizontally (Eq. 3) and $90.9 \%$ (subject variability: $71.3-106.5 \%$ ) vertically (Eq. 4) at the end of the orientation process. Note that this was a better performance than after the first orientation saccade (see Fig. 5 and Table 1). Furthermore, the final compensation for the smooth eye displacement (extraretinal signal) was $53.4 \%$ (subject variability: $36.5-87.2 \%$ ) horizontally (Eq. 3) and $57.1 \%$ (subject variability: $45.0-73.3 \%$ ) vertically (Eq. 4). Thus Eqs. 3 and 4 provided a measure of the accuracy of the orientation process that compensated almost perfectly for $\mathrm{PE}_{\mathrm{F}}$ and accounted for $\sim 55 \%$ of SED (see compensation index, Fig. 9, $B-D)$. It is worth noting that we computed the compensation index only if a saccade took place, whereas the regression analysis of Eqs. 3 and 4 included all trials irrespectively of the number of executed saccades. Our values were lower than the previously reported $70 \%$ overall SED compensation in the case of target localization during smooth anticipatory eye movements (Blohm et al. 2003). The regression analysis for FAR control provided results similar to the test trials (data not shown).

$\mathrm{PE}_{\text {end,Y }}=(-.703 \pm .035)+(.091 \pm .005) * \mathrm{PE}_{\mathrm{F}, \mathrm{Y}}$

$$
-(.429 \pm .010) * \mathrm{SED}_{\text {end, },} \quad(R=0.559, P<0.001)
$$

As a consequence, the saccadic system compensated differently for the retinal error information $\left(\mathrm{PE}_{\mathrm{F}}\right)$ and the extraretinal

\section{I S C U S S I O N}

The programming of memory-guided saccades during smooth eye movements reflects the performance of the system in maintaining space constancy. To investigate this mecha- 
A

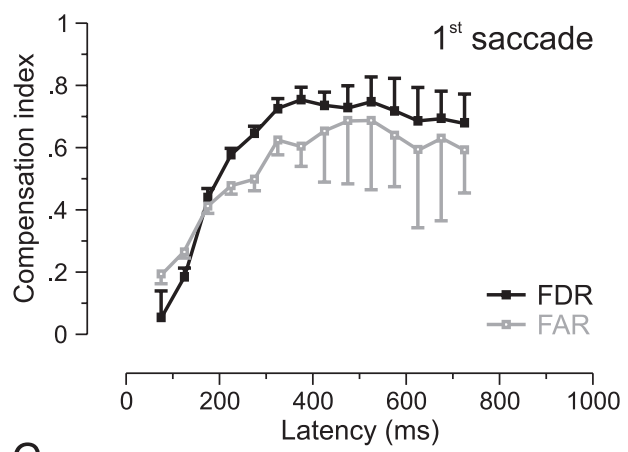

C

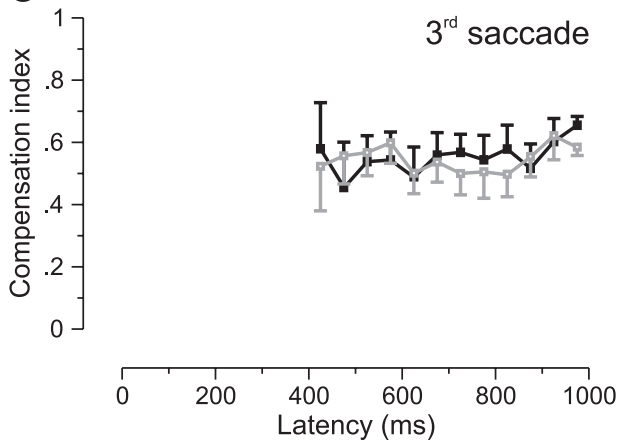

B

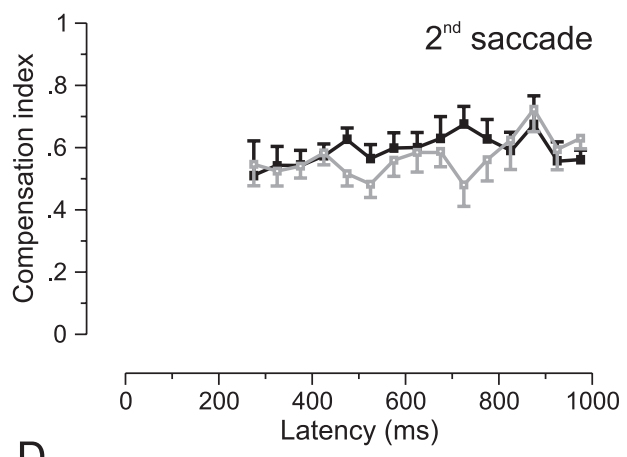

$4^{\text {th }}$ saccade

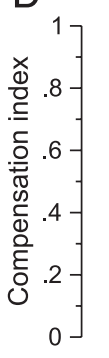

FIG. 9. Consequences of the secondary "catch-up" saccades. Compensation indices as a function of saccade latency with respect to the onset of the flash. Black data are FDR trials; gray data stand for FAR controls. Squares and whiskers indicate mean and SE. $A$ : compensation index for the 1 st saccade (for FDR: the same data as in Fig. $4 B$ but with larger bin sizes). $B$ : compensation index of the 2nd saccade $(n=3,378)$. $C$ : effect of the 3 rd saccade on the compensation index $(n=$ 1,743). $D$ : compensation index for the 4 th saccade $(n=707)$. nism, we presented a briefly flashed target during smoothpursuit eye movements and analyzed the characteristics of the first saccade. As a result, we found that short-latency saccades were better correlated with retinal error than with spatial error, whereas the opposite was the case for longer-latency saccades. The saccadic system approximately needed $175 \mathrm{~ms}$ before extraretinal information about the smooth eye displacement could be used in saccade programming. This behavior was also reflected in the latency distribution, where we found two distinct modes - a short-latency and a longer-latency modeseparated at $\sim 175 \mathrm{~ms}$. We interpret our results as evidence for the existence of two different neural processes for saccade programming: one fast but inaccurate and the other slower but spatially more accurate.

\section{Saccadic reaction times}

We observed a bimodal distribution of saccade latencies in our test trials and in both control data sets. Similar distributions have been observed previously during saccadic "gap" and "overlap" paradigms (Fischer et al. 1993, 1997; Reulen 1984a,b; Saslow 1967). To quantify our bimodal first saccade latency distribution, we fitted a double-recinormal distribution to our data. We used this particular distribution because it described very well our data with only very few parameters. However, as already mentioned in RESULTS, this procedure is theoretically equivalent to the hypothesis of two distinct saccade trigger mechanisms of the LATER type (Carpenter and Williams 1995; Reddi and Carpenter 2000; Reddi et al. 2003) that work in parallel and do not interact. Although we cannot prove that such a mechanism exists, it is supported by our data because all latency distributions agree with the hypothesis of two parallel decision processes. As we demonstrated in Fig. 8, the system's decision between both processes depended on the set of sensory parameters (distance of the target from the fovea and eye velocity) at the moment of the flash. Indeed, the effect of position error on saccade latency has previously been described (Bell et al. 2000; Clark 1999; Hodgson 2002; Kalesnykas and Hallett 1994), and it makes sense that the system needs more time for small position errors to decide whether it is necessary to trigger a saccade. We did also observe this effect for our fixation control trials (data not shown) and our "flash after ramp" (FAR) controls (Fig. 8, $A$ and $B$ ), i.e., the longer latency mode essentially resulted from flashes presented at small position errors. The influence of eye velocity on saccade latency however was-to our knowledge-a novel finding. Because for large smooth-pursuit velocities the error after a short latency saccade (retinally programmed) would be big, the system might prefer to wait longer for extraretinal smooth eye displacement information to become available (see Fig. 4). This "waiting strategy" allowed the system to perform spatially more accurate initial saccades. Thus the relationship between saccade latency and eye velocity described the system's tradeoff between speed and accuracy.

We showed in Fig. 7 that the mean saccadic latency is shorter for flashes presented in the direction of the movement (foveopetal) than for flashed targets presented in the opposite direction (foveofugal). This is compatible with previous findings for horizontal catch-up saccades during smooth pursuit of continuously visible targets (Kanai et al. 2003; Tanaka et al. 1998). In these studies, saccades in the same direction as smooth pursuit had shorter latencies than saccades in the opposite direction. In addition, this latency asymmetry was also present in our FAR control trials where no visible target was present. Kanai et al. (2003) hypothesized that this difference in latencies is due to the inhibition of saccades to previously attended positions during smooth pursuit, a particular instantiation of the "inhibition of return" (IOR) effect (see Klein 2000 for a review). At first sight, our data seemed to be compatible with such a hypothesis. However, our 2-D para- 
digm allowed us for the first time to show that this latency asymmetry is a hemifield effect and not related to a "focus of attention," as IOR would predict (Maylor and Hockey 1985; Posner et al. 1985). Nevertheless, our results would be compatible with an attentional facilitation in the direction of the movement, if this facilitation was extended to the whole foveopetal hemifield and was not restricted to a focus of attention (Maylor and Hockey 1985; Posner et al. 1985). The purpose of such a hemifield bias could simply be to facilitate movement in the direction of heading.

\section{Saccades compensate for self-motion}

The analysis of the saccade latencies revealed a bimodal distribution. The presence of these two different saccade trigger processes was also reflected in the way saccades were programmed. We showed indeed that saccades with short latencies $(<175 \mathrm{~ms})$ were programmed using the only available retinal information, i.e., position error at the moment of the flash. This is in accordance with previous studies (Gellman and Fletcher 1992; McKenzie and Lisberger 1986) and contrasts with the situation where continuous visual feedback is present. In the latter condition, orientation saccades to the object's spatial location are programmed using two types of retinal information, i.e., position error and the relative velocity of the eyes with respect to the target (retinal slip) (de Brouwer et al. 2001, 2002; Gellman and Carl 1991; Keller and Johnsen 1990; Ron et al. 1989). However, although retinal information about smooth self-motion was absent in our experiment, longerlatency $(>175 \mathrm{~ms})$ saccades used a different programming mechanism that included extraretinal information about the smooth eye displacement in addition to the retinal position error.

All previous studies support our results. McKenzie and Lisberger (1986) reported that short-latency memory-guided saccades during pursuit eye movements were retinally coded. However, one monkey showed a bias of the suggested retinally saccade coding toward a more accurate spatial amplitude programming, that the authors attributed to the monkey's participation in previous smooth tracking experiments. However, this monkey also had particularly long mean saccade reaction times compared with the two other monkeys. We believe that our results explain the third monkey's bias toward the spatial coding hypothesis simply as a consequence of longer latencies. Other studies showed that when memoryguided saccades were executed after a delay period, smooth self-motion was compensated and saccades were spatially accurate (Baker et al. 2003; Herter and Guitton 1998; Ohtsuka 1994; Schlag et al. 1990; Zivotofsky et al. 1996), which is fully compatible with our results. Thus we described here the missing piece in the puzzle of self-motion integration, i.e., the temporal transition between the retinal and spatial representation of the visual world in the oculomotor system.

Initially, McKenzie and Lisberger (1986) used a paradigm similar to our FAR controls in an attempt to differentiate between two different types of saccade models, i.e., position and displacement models. Position models (Robinson 1975; Van Gisbergen et al. 1981) assume that the signal of desired eye position is compared with a signal of the current position of the eye in the orbit to generate a motor command. In contrast, displacement models (Jürgens et al. 1981) assume that a desired displacement — rather than a desired position — signal is used to drive the saccadic eye movement. During a saccade, this desired displacement is compared with an internal representation of the movement already executed to produce the movement command. McKenzie and Lisberger (1986) trained monkeys to make saccades to flashes memorized during smooth eye movements to test the position versus the displacement model. The monkeys made saccades to the retinal position of the flash (Gellman and Fletcher 1992; McKenzie and Lisberger 1986), which validated the displacement model because the position model would have predicted a spatially accurate eye movement. However, our data reported here as well as previous findings (Baker et al. 2003; Herter and Guitton 1998; Ohtsuka 1994; Schlag et al. 1990; Zivotofsky et al. 1996) support the idea that if more time is available to the system before the onset of the orienting eye movement, saccades can be spatially accurate. This implies that there must be an additional mechanism available to perform this retinal to spatial transformation, but apparently, such a mechanism takes some time and is not implemented at the level of the saccadic displacement integrator. Hereafter, we will propose a neural mechanism that could account for all the data.

\section{Hypothesized underlying neural mechanisms}

We believe that our results reflect the presence of two different neural mechanisms for retinal and extraretinal information processes characterized by different processing times. In this section, we will shortly lay out one hypothesis of the underlying neural pathways that might be involved in the integration of smooth-pursuit eye movements and the orientation to memorized targets.

The major forebrain and midbrain structures involved in the programming and/or control of saccades are the posterior parietal cortex (PPC), the frontal eye fields (FEFs), the dorsolateral prefrontal cortex (DLPC), the basal ganglia, the cerebellum (CB), and the superior colliculus (SC) (see for a review Krauzlis and Stone 1999; Leigh and Zee 1999). It is generally accepted that SC is essential to generate short-latency saccades (Fischer and Ramsperger 1986; Munoz and Wurtz 1992; Schiller et al. 1987). Indeed, Schiller at al. (1987) showed a lateralized absence of short-latency saccades in monkeys after unilateral SC ablation, whereas longer-latency saccades were still present. This was not the case for FEF ablation, which had no long-term effect on saccade latencies (Schiller et al. 1987). Therefore we propose that the short latency saccades we reported here were essentially mediated by a fast "striatalcollicular pathway" (Leigh and Zee 1999). This contrasts with longer-latency saccades that are known to involve most of the above-cited structures including PPC.

It has previously been suggested (Duhamel et al. 1992; Heide et al. 1995), that PPC plays a key role to account for extraretinal signals (Tobler et al. 2001) when keeping track of self-motion to ensure space constancy. Indeed, the lateral intraparietal area (LIP) and area 7a in PPC receive information about upcoming saccades to update the spatial representation of visual stimuli (Andersen et al. 1985; Bremmer et al. 1997). Therefore we propose that the memorized flash position in our experiment is stored in PPC (Barash et al. 1991; Paré and Wurtz 1997; Pierrot-Deseilligny et al. 1991) and updated by smooth eye displacement information when it becomes avail- 
able. The smooth eye displacement signal could result from an integration process of the smooth motor command (Blohm et al. 2003), which might take some time. Such a process could involve parts of the cerebellum-highly involved in generating smooth pursuit (Lisberger et al. 1987; Pola and Wyatt 1991) and smooth eye displacement information could be projected either directly or via the thalamus (Clower et al. 2001) to PPC to update the spatial representation of the flash. This would explain why in our data smooth eye displacement information took $\sim 175 \mathrm{~ms}$ to become available to the saccadic system. According to this view, the classical saccade pathway would be responsible for retinally coded saccades. An additional feedback pathway for the integration of smooth-pursuit eye movements could then be added to these classical structures to ensure space constancy during smooth eye movements. Our observation that smooth eye movement integration was characterized by a delay $(\sim 175 \mathrm{~ms})$ implies that the system only compensates for the smooth eye displacement that has already been integrated. This might explain why the compensation mechanism is not an all-or-none process. However, we cannot exclude a possible role of proprioception (Steinbach 2000) for the spatial orientation toward the flash, although proprioception is thought not to be a predominant source for spatial localization (Weir 2000) and the control of eye movements in general (Lewis et al. 2001).

We suggest using our original 2-D paradigm in neural recording studies to identify the neural correlates underlying the monitoring of smooth pursuit. The presence of two separate control modes for memory-guided saccades during smooth eye movements could provide a new testing bench to investigate the neural processes of smooth motion integration. More generally, our results provide a new path to investigate the interaction between smooth pursuit and saccadic systems.

\section{A C K N O W LED G MEN TS}

We thank the anonymous referees for very helpful suggestions concerning the presentation of our data. The scientific responsibility rests with its authors.

\section{G R A N T S}

This work was supported by the Fonds National de la Recherche Scientifique; the Fondation pour la Recherche Scientifique Médicale; the Belgian program on Interuniversity Attraction Poles initiated by the Belgian Federal Science Policy Office; and internal research grant (Fonds Spéciaux de Recherche) of the Université catholique de Louvain.

\section{REFERENCES}

Andersen RA, Essick GK, and Siegel RM. Encoding of spatial location by posterior parietal neurons. Science 230: 456-458, 1985.

Aslin RN and Shea SL. The amplitude and angle of saccades to double-step target displacements. Vision Res 27: 1925-1942, 1987.

Baker JT, Harper TM, and Snyder LH. Spatial memory following shifts of gaze. I. Saccades to memorized world-fixed and gaze-fixed targets. $\mathrm{J} \mathrm{Neu}$ rophysiol 89: 2564-2576, 2003.

Barash S, Bracewell RM, Fogassi L, Gnadt JW, and Andersen RA. Saccade-related activity in the lateral intraparietal area. II. Spatial properties. J Neurophysiol 66: 1109-1124, 1991.

Becker W and Jürgens R. An analysis of the saccadic system by means of double step stimuli. Vision Res 19: 967-983, 1979.

Bell AH, Everling S, and Munoz DP. Influence of stimulus eccentricity and direction on characteristics of pro- and antisaccades in non-human primates. J Neurophysiol 84: 2595-2604, 2000.

Blohm G, Missal M, and Lefevre P. Interaction between smooth anticipation and saccades during ocular orientation in darkness. J Neurophysiol 89: 1423-1433, 2003.
Bremmer F, Distler C, and Hoffmann KP. Eye position effects in monkey cortex. II. Pursuit- and fixation-related activity in posterior parietal areas LIP and 7A. J Neurophysiol 77: 962-977, 1997.

Bridgeman B. A review of the role of efference copy in sensory and oculomotor control systems. Ann Biomed Eng 23: 409-422, 1995.

Carpenter RH and Williams ML. Neural computation of log likelihood in control of saccadic eye movements. Nature 377: 59-62, 1995.

Clark JJ. Spatial attention and latencies of saccadic eye movements. Vision Res 39: 585-602, 1999.

Clower DM, West RA, Lynch JC, and Strick PL. The inferior parietal lobule is the target of output from the superior colliculus, hippocampus, and cerebellum. J Neurosci 21: 6283-6291, 2001.

Collewijn H, van der Mark F, and Jansen TC. Precise recording of human eye movements. Vision Res 15: 447-450, 1975.

Dassonville P, Schlag J, and Schlag-Rey M. The frontal eye field provides the goal of saccadic eye movement. Exp Brain Res 89: 300-310, 1992.

de Brouwer S, Missal M, Barnes G, and Lefevre P. Quantitative analysis of catch-up saccades during sustained pursuit. J Neurophysiol 87: 1772-1780, 2002.

de Brouwer S, Missal M, and Lefèvre $\mathbf{P}$. Role of retinal slip in the prediction of target motion during smooth and saccadic pursuit. J Neurophysiol 86: 550-558, 2001.

Deubel H, Bridgeman B, and Schneider WX. Immediate post-saccadic information mediates space constancy. Vision Res 38: 3147-3159, 1998.

Dominey PF, Schlag J, Schlag-Rey M, and Arbib MA. Colliding saccades evoked by frontal eye field stimulation: artifact or evidence for an oculomotor compensatory mechanism underlying double-step saccades? Biol Cybern 76: 41-52, 1997.

Duhamel JR, Colby CL, and Goldberg ME. The updating of the representation of visual space in parietal cortex by intended eye movements. Science 255: 90-92, 1992.

Fischer B, Gezeck S, and Hartnegg K. The analysis of saccadic eye movements from gap and overlap paradigms. Brain Res Brain Res Protoc 2 : 47-52, 1997.

Fischer B and Ramsperger E. Human express saccades: effects of randomization and daily practice. Exp Brain Res 64: 569-578, 1986.

Fischer B, Weber H, Biscaldi M, Aiple F, Otto P, and Stuhr V. Separate populations of visually guided saccades in humans: reaction times and amplitudes. Exp Brain Res 92: 528-541, 1993.

Gellman RS and Carl JR. Motion processing for saccadic eye movements in humans. Exp Brain Res 84: 660-667, 1991.

Gellman RS and Fletcher WA. Eye position signals in human saccadic processing. Exp Brain Res 89: 425-434, 1992.

Goossens HH and Van Opstal AJ. Local feedback signals are not distorted by prior eye movements: evidence from visually evoked double saccades. J Neurophysiol 78: 533-538, 1997.

Hallett PE and Lightstone AD. Saccadic eye movements to flashed targets. Vision Res 16: 107-114, 1976a.

Hallett PE and Lightstone AD. Saccadic eye movements towards stimuli triggered by prior saccades. Vision Res 16: 99-106, 1976b.

Heide W, Blankenburg M, Zimmermann E, and Kompf D. Cortical control of double-step saccades: implications for spatial orientation. Ann Neurol 38: 739-748, 1995.

Helsinki. World Medical Organization: Declaration of Helsinki. Brit Med J 313: 1448-1449, 1996.

Herter TM and Guitton D. Human head-free gaze saccades to targets flashed before gaze-pursuit are spatially accurate. J Neurophysiol 80: 2785-2789, 1998.

Hodgson TL. The location marker effect. Saccadic latency increases with target eccentricity. Exp Brain Res 145: 539-542, 2002.

Jürgens R, Becker W, and Kornhuber HH. Natural and drug-induced variations of velocity and duration of human saccadic eye movements: evidence for a control of the neural pulse generator by local feedback. Biol Cybern 39: 87-96, 1981.

Kalesnykas RP and Hallett PE. Retinal eccentricity and the latency of eye saccades. Vision Res 34: 517-531, 1994.

Kanai R, Van Der Geest N, and Frens A. Inhibition of saccade initiation by preceding smooth pursuit. Exp Brain Res 148: 300-307, 2003.

Keller EL, Gandhi NJ, and Weir PT. Discharge of superior collicular neurons during saccades made to moving targets. J Neurophysiol 76: 3573-3577, 1996.

Keller E and Johnsen SD. Velocity prediction in corrective saccades during smooth-pursuit eye movements in monkey. Exp Brain Res 80: 525-531, 1990 . 
Klein RM. Inhibition of return. Trends Cogn Sci 4: 138-147, 2000.

Krauzlis RJ and Stone LS. Tracking with the mind's eye. Trends Neurosci 22: 544-550, 1999.

Leigh JR and Zee DS. The Neurology of Eye Movements. New York: Oxford, 1999.

Lewis RF, Zee DS, Hayman MR, and Tamargo RJ. Oculomotor function in the rhesus monkey after deafferentation of the extraocular muscles. Exp Brain Res 141: 349-358, 2001.

Lisberger SG, Morris EJ, and Tychsen L. Visual motion processing and sensory-motor integration for smooth pursuit eye movements. Annu Rev Neurosci 10: 97-129, 1987.

May JG, Keller EL, and Suzuki DA. Smooth-pursuit eye movement deficits with chemical lesions in the dorsolateral pontine nucleus of the monkey. J Neurophysiol 59: 952-977, 1988.

Maylor EA and Hockey R. Inhibitory component of externally controlled covert orienting in visual space. J Exp Psychol Hum Percept Perform 11: 777-787, 1985.

Mays LE and Sparks DL. Saccades are spatially, not retinocentrically, coded. Science 208: 1163-1165, 1980

McKenzie A and Lisberger SG. Properties of signals that determine the amplitude and direction of saccadic eye movements in monkeys. J Neurophysiol 56: 196-207, 1986.

Munoz DP and Wurtz RH. Role of the rostral superior colliculus in active visual fixation and execution of express saccades. J Neurophysiol 67: 1000-1002, 1992.

Mushiake H, Fujii N, and Tanji J. Microstimulation of the lateral wall of the intraparietal sulcus compared with the frontal eye field during oculomotor tasks. J Neurophysiol 81: 1443-1448, 1999.

Niemann T and Hoffmann KP. Motion processing for saccadic eye movements during the visually induced sensation of ego-motion in humans. Vision Res 37: 3163-3170, 1997.

Ohtsuka K. Properties of memory-guided saccades toward targets flashed during smooth pursuit in human subjects. Invest Ophthalmol Vis Sci 35: 509-514, 1994.

Paré M and Wurtz RH. Monkey posterior parietal cortex neurons antidromically activated from superior colliculus. J Neurophysiol 78: 3493-3497, 1997.

Pierrot-Deseilligny C, Rivaud S, Gaymard B, and Agid Y. Cortical control of memory-guided saccades in man. Exp Brain Res 83: 607-617, 1991.

Pola J and Wyatt HJ. Smooth pursuit: response characteristics, stimuli and mechanisms. In: Eye Movements: Vision and Visual Dysfunction, edited by Carpenter R. Houndmills, UK: Macmillan, 1991, p. 138-156.

Posner M, Rafal R, Choate L, and Vaughan J. Inhibition of return: neural basis and function. Cognit Neuropsychol 2: 211-228, 1985.

Rashbass C. The relationship between saccadic and smooth tracking eye movements. J Physiol 159: 326-338, 1961.

Reddi BA, Asrress KN, and Carpenter RH. Accuracy, information, and response time in a saccadic decision task. J Neurophysiol 90: 3538-3546, 2003.

Reddi BA and Carpenter RH. The influence of urgency on decision time. Nat Neurosci 3: 827-830, 2000.

Reulen JP. Latency of visually evoked saccadic eye movements. I. Saccadic latency and the facilitation model. Biol Cybern 50: 251-262, 1984a.

Reulen JP. Latency of visually evoked saccadic eye movements. II. Temporal properties of the facilitation mechanism. Biol Cybern 50: 263-271, 1984b.

Robinson DA. A method of mesuring eye movement using a scleral search coil in a magnetic field. IEEE Trans Biomed Eng BME- 10: 137-145, 1963.
Robinson DA. Oculomotor control signals. In: Basic Mechanisms of Ocular Motility and Their Clinical Implications, edited by Lennerstrand G and Bach-y-Rita P. Oxford: Pergamon, 1975, p. 337-374.

Ron S, Vieville T, and Droulez J. Use of target velocity in saccadic programming. Brain Behav Evol 33: 85-89, 1989.

Saslow MG. Effects of components of displacement-step stimuli upon latency for saccadic eye movement. J Opt Soc Am 57: 1024-1029, 1967.

Schiller PH, Sandell JH, and Maunsell JH. The effect of frontal eye field and superior colliculus lesions on saccadic latencies in the rhesus monkey. J Neurophysiol 57: 1033-1049, 1987.

Schlag J and Schlag-Rey M. Colliding saccades may reveal the secret of their marching orders. Trends Neurosci 13: 410-415, 1990.

Schlag J, Schlag-Rey M, and Dassonville P. Interactions between natural and electrically evoked saccades. II. At what time is eye position sampled as a reference for the localization of a target? Exp Brain Res 76: 548-558, 1989.

Schlag J, Schlag-Rey M, and Dassonville P. Saccades can be aimed at the spatial location of targets flashed during pursuit. J Neurophysiol 64: 575581,1990

Smeets JBJ and Bekkering H. Prediction of saccadic amplitude during smooth pursuit eye movements. Hum Move Sci 19: 275-295, 2000.

Sommer MA. The role of the thalamus in motor control. Curr Opin Neurobiol 13: 663-670, 2003.

Sommer MA and Wurtz RH. A pathway in primate brain for internal monitoring of movements. Science 296: 1480-1482, 2002.

Sommer MA and Wurtz RH. What the brain stem tells the frontal cortex. I. Oculomotor signals sent from superior colliculus to frontal eye field via mediodorsal thalamus. J Neurophysiol 91: 1381-1402, 2004a.

Sommer MA and Wurtz RH. What the brain stem tells the frontal cortex. II. Role of the SC-MD-FEF pathway in corollary discharge. J Neurophysiol 91: 1403-1423, 2004b.

Stark L and Bridgeman B. Role of corollary discharge in space constancy. Percept Psychophys 34: 371-380, 1983.

Steinbach MJ. The palisade ending: an afferent source for eye position information in humans. In: Advances in Strabismus Research: Basic and Clinical Aspects, edited by Lennerstrand G and Ygge J. London: Portland, 2000, p. 33-42.

Tanaka M, Yoshida T, and Fukushima K. Latency of saccades during smooth-pursuit eye movement in man. Directional asymmetries. Exp Brain Res 121: 92-98, 1998.

Thurston SE, Leigh RJ, Crawford T, Thompson A, and Kennard C. Two distinct deficits of visual tracking caused by unilateral lesions of cerebral cortex in humans. Ann Neurol 23: 266-273, 1988.

Tian J, Schlag J, and Schlag-Rey M. Testing quasi-visual neurons in the monkey's frontal eye field with the triple-step paradigm. Exp Brain Res 130: 433-440, 2000.

Tobler PN, Felblinger J, Burki M, Nirkko AC, Ozdoba C, and Muri RM. Functional organisation of the saccadic reference system processing extraretinal signals in humans. Vision Res 41: 1351-1358, 2001.

Van Gisbergen JA, Robinson DA, and Gielen S. A quantitative analysis of generation of saccadic eye movements by burst neurons. J Neurophysiol 45 : 417-442, 1981.

Weir CR. Spatial localisation: does extraocular muscle proprioception play a role? Graefes Arch Clin Exp Ophthalmol 238: 868-873, 2000.

Zivotofsky AZ, Rottach KG, Averbuch-Heller L, Kori AA, Thomas CW, Dell'Osso LF, and Leigh RJ. Saccades to remembered targets: the effects of smooth pursuit and illusory stimulus motion. J Neurophysiol 76: 3617 $3632,1996$. 